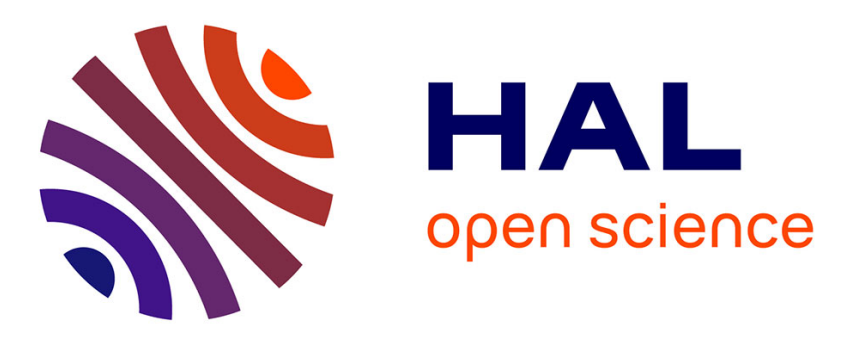

\title{
Frey procedure combined with biliary diversion in chronic pancreatitis
}

Aude Merdrignac, Damien Bergeat, Michel Rayar, Yann Harnoy, Kathleen

Turner, Laetitia Courtin-Tanguy, Karim Boudjema, B. Meunier, Laurent Sulpice

\section{To cite this version:}

Aude Merdrignac, Damien Bergeat, Michel Rayar, Yann Harnoy, Kathleen Turner, et al.. Frey procedure combined with biliary diversion in chronic pancreatitis. Surgery, 2016, 160 (5), pp.1264-1270. 10.1016/j.surg.2016.05.006 . hal-01414694

\section{HAL Id: hal-01414694 https://hal-univ-rennes1.archives-ouvertes.fr/hal-01414694}

Submitted on 3 Feb 2017

HAL is a multi-disciplinary open access archive for the deposit and dissemination of scientific research documents, whether they are published or not. The documents may come from teaching and research institutions in France or abroad, or from public or private research centers.
L'archive ouverte pluridisciplinaire HAL, est destinée au dépôt et à la diffusion de documents scientifiques de niveau recherche, publiés ou non, émanant des établissements d'enseignement et de recherche français ou étrangers, des laboratoires publics ou privés. 


\section{Frey procedure combined with biliary diversion in chronic}

\section{pancreatitis}

Merdrignac $A^{1,2,3}$, Bergeat $D^{1,2,3}$, Rayar $M^{1,2}$, Harnoy $Y^{1,2,3}$, Turner $K^{1,2}$, Tanguy $L^{1,2,3}$,

Boudjema $K^{1,2}$, Meunier $B^{1,2}$ and Sulpice $L^{1,2,3}$.

${ }^{1} \mathrm{CHU}$ Rennes, Service de Chirurgie Hépatobiliaire et Digestive, F-35033 Rennes, France

2 Université Rennes1, Faculté de médecine, F-35043 Rennes, France

${ }^{3}$ INSERM, U991, Foie métabolismes et cancer, F-35033 Rennes, France

Correspondence:

Pr Sulpice Laurent

2, rue Henri Le Guilloux

35033 Rennes

laurent.sulpice@chu-rennes.fr

phone : +33299288498

fax : +33 299284129

\section{Original article}

This study has been presented previously at the $11^{\text {th }}$ French congress of digestive and hepato-bilio-pancreatic surgery in November 2015.

Source of financial supports: This study did not received financial supports.

Conflicts of interest: The authors have no conflicts of interest to declare.

Word count for the text: 2362

Word count for the abstract: 202

Keywords: Chronic pancreatitis; Bile duct obstruction, Frey procedure

Running Head: Frey procedure and chronic pancreatitis

Author's contribution: AM and LS designed and conducted the study, performed the analysis and interpretation of the data, and wrote and finalized the manuscript. $\mathrm{AM}, \mathrm{MR}, \mathrm{YH}, \mathrm{KT}$ and $\mathrm{LT}$ collected the data. DB performed the statistical analysis. KB, AM and LS analyzed and interpreted the data and revised the manuscript. BM and LS revised the manuscript and gave final approval for publication. 


\section{Abstract}

Background:

The Frey procedure (FP) has become the standard surgical treatment in chronic painful pancreatitis. Biliary diversion could be combined when associated with common bile duct (CBD) obstruction. The aim of the present study was to evaluate the impact of the type of biliary diversion combined with FP on late morbidity.

Methods:

The data from consecutive patients undergoing the FP and having a minimum followup of 2 years were extracted from a maintained prospective database. The mean endpoint was the rate of secondary biliary stricture after FP combined with biliary diversion (bilioenteric anastomosis or CBD reinsertion in the resection cavity).

Results:

Between 2006 and 2013, 55 consecutive patients underwent FP. Twenty-nine patients had CBD obstruction (52.7\%). The technique of biliary diversion resulted in bilioenteric anastomosis in 19 patients (65.5\%) and CBD reinsertion in 10 patients (34.5\%). Preoperative characteristics and early surgical outcomes were comparable. Pain control was similar. There was significantly more secondary biliary stricture after CBD reinsertion than after bilioenteric anastomosis ( $60 \%$ vs. $11 \%, \mathrm{p}=0.008)$.

Conclusion:

Combined bilioenteric anastomosis during FP is an efficient technique to treat CBD obstruction that complicates chronic painful pancreatitis. Bilioenteric anastomosis was associated with less secondary biliary stricture than CBD reinsertion in the pancreatic resection cavity. 


\section{Introduction}

Pain is the main symptom caused by chronic pancreatitis (CP) ${ }^{1}$. However, an inflammatory pancreatic head mass could also affect adjacent organs. Common bile duct (CBD) stricture appears in 3 to $46 \%$ of patients and could lead to chronic cholestasis, cholangitis, and eventually to secondary biliary cirrhosis ${ }^{2}$. In addition to pancreatic head cancer, painful inflammatory pancreatic head mass has long been considered to be a classic indication for pancreaticoduodenectomy (PD). Morbidity and mortality rates of PD have decreased during the last decades. Nevertheless, various surgeons have tried to introduce more conservative procedures, such as duodenum preserving pancreatic head resection, that cause less morbidity ${ }^{3}$. The Frey procedure (FP), which was first described in 1987 and combines inflammatory head mass resection and pancreatic main duct drainage, has become a suitable alternative ${ }^{4}$.

However, in case of CBD compression associated with a pancreatic head mass, there is no guideline on the method to remove this compression during FP. Pancreatic mass head resection or enucleation may be sufficient in some cases to restore bile flow. However, an associated procedure is needed if intraoperative cholangiography still indicates a biliary stricture. This drainage is commonly achieved with bilioenteric anastomosis. The type of bilioenteric anastomosis (Roux-en-Y choledochojejunostomy or choledochoduodenostomy) depends on surgeon's awareness of the situation.

In 1997, Izbicki described an alternative surgical approach consisting of the reinsertion of the distal $\mathrm{CBD}$ in the resection cavity during duodenum-preserving pancreatic head resection ${ }^{5}$. Since the description of this procedure, only a few authors have studied this technique and have not made a significant conclusion ${ }^{6}$. 
The present study aimed to compare morbidity and follow-up between two types of biliary diversion combined with FP for painful chronic pancreatitis complicated by CBD stricture. 


\section{Methods}

\section{Patients}

A database of consecutive patients who underwent the FP in a tertiary centre has been created and maintained prospectively since 2006. Data were collected regarding demographics, preoperative procedures (endoscopic, radiologic), surgical variables, length of hospital stay, postoperative morbidity, and follow-up. Patients operated between 2006 and 2013 were included in the analyses (allowing at least 2 years of follow-up except for patients who died prematurely or were lost to follow up). Diagnosis of chronic pancreatitis was based on the clinical (clinical history, physical examination) and imaging findings (computed tomographic scan, magnetic resonance cholangiopancreatography, echoendoscopy). Indication for surgery was systematically determined during a multidisciplinary meeting including surgeons, gastroenterologists and radiologists.

\section{Surgical procedure}

FP was performed by one senior pancreatic surgeon (LS) according to the technique first described in 1987 by Frey ${ }^{4}$. The need for biliary diversion was determined preoperatively or perioperatively when CBD stricture persisted as observed by perioperative cholangiography. The type of biliary diversion chosen in case of CBD stricture depended on the accessibility of the CBD in the resection cavity and was left to the discretion of the surgeon.

The technique of $\mathrm{CBD}$ reinsertion combined a 1 centimeter longitudinal cut of the distal CBD in the pancreatic head resection cavity and an anastomosis to pancreatic parenchyma using 5-0 polydioxanone interrupted sutures. A Roux-en-Y choledochojejunostomy was performed if bilioenteric anastomosis was chosen. The same Roux-en-Y jejunal loop was used for the bilioenteric anastomosis and for the 
pancreaticojejunal anastomosis. The distal extremity of the jejunal loop was first anastomosed with the pancreas.

\section{Definitions}

The postoperative morbidity was defined as any complication that occurred within 90 days after surgery. The complications were categorized according to the Dindo and Clavien classification ${ }^{7}$. Major complications were categorized as grades III to $\mathrm{V}$ in the Dindo and Clavien classification. Postoperative pancreatic fistula was classified into three groups according to the criteria given by the International Study Group of Pancreatic Fistula ${ }^{8}$. Postoperative delayed gastric emptying was classified according to the criteria given by the International Study Group of Pancreatic Surgery (ISGPS) but only grade $\mathrm{B}$ and $\mathrm{C}$ were used for this study as our centre policy was to maintain the nasogastric tube until at least postoperative day 59 . Postpancreatectomy haemorrhage including intra- and extra-luminal bleeding was classified according to the ISGPS definition ${ }^{10}$.

Biliary fistula was defined as the appearance of bile in peritoneal drains.

The primary biliary dilatation was suspected on preoperative cholangioMRI and/or CTscan, and confirmed intraoperatively by systematic cholangiography.

The secondary biliary stricture was suspected on biological laboratory results or occurrence of cholangitis during follow-up and systematically confirmed by cholangioMRI before treatment.

Pain control was assessed during postoperative follow up at 3, 6, 12 and 24 months and defined as an absence of morphinics use.

\section{Statistical analysis}

Qualitative variables are expressed as numbers with percentages and were compared using Chi-square or Fisher exact tests as appropriate. Quantitative 
variables are expressed as mean values \pm the standard deviation and were compared using Mann-Whitney $U$ test. P-values less than 0.05 were considered statistically significant. Analyses were performed with R statistical software (available: http://www.r-project.org/).

\section{Results}

Fifty-five consecutive patients underwent FP for painful CP between 2006 and 2013. Twenty-nine (53\%) patients had painful CP complicated with CBD stricture. Mean follow-up was $37.25 \pm 24.69$ months (range: 1.8-104.5). The mean volume of pancreatic enucleation was $27.3 \pm 19 \mathrm{~cm}^{3}$ and the mean larger diameter of the specimen was $4.2 \pm 1.2 \mathrm{~cm}$.

The clinical characteristics of patients according to the presence of biliary dilatation are compared in table 1. Patients were comparable with respect to exocrine insufficiency rate $(p=0.84)$, diabetes rate $(p=0.4)$ and ASA score $(p=0.42)$.

Endoscopic biliary stenting was done prior to surgical biliary diversion in 5 patients (17.2\%). Biliary preoperative dilatation did not influence postoperative outcomes.

Table 2 compares data according to the technique used to restore bile flow in patients presenting biliary dilatation. A bilioenteric anastomosis was performed in 19 patients (66\%) and a CBD reinsertion in 10 patients (34\%). Preoperative data were comparable. Operating time for the bilioenteric anatomosis was longer than for CBD reinsertion into the pancreatic resection cavity $(p=0.02)$. Postoperative outcomes were comparable.

The incidence of severe complications was $13.8 \%$ in the biliary dilatation group and was comparable between the 2 types of biliary diversion. Severe complications for the 5 patients were: post-operative haemorrhage (grade 3 and requiring surgical 
revision) for 3 patients, pancreatic fistula (grade 2 treated by radiologic drainage of intra-abdominal abscess), and postoperative respiratory distress due to atelectasis (hospitalization in intensive care unit).

Two patients with bilioenteric anastomosis developed biliary leakage treated by maintained peritoneal drainage. This complication prolonged the hospitalization to 15 days in one case with reoperation 16 months later for secondary biliary stricture. In the other case, a grade 3 haemorrhage was associated to biliary leakage. This patient did not developed secondary biliary stricture.

\section{Secondary biliary stricture rate}

Rate of secondary biliary stricture was significantly greater after CBD reinsertion than after bilioenteric anastomosis (60\% vs. $11 \%, \mathrm{p}=0.008)$.

Secondary biliary stricture appeared in 8 patients with biliary diversion and was treated either by radiologic, endoscopic or surgical procedures (table 2). Diagnosis was done after occurrence of cholestasis in 7 patients and acute severe cholangitis in one patient. Mean interval between surgery and the diagnosis of secondary biliary stricture was $7.62 \pm 4.37$ months.

Among the 6 patients with $\mathrm{CBD}$ reinsertion, the first three patients with secondary biliary stricture were treated with surgical reintervention between 2007 and 2009 . After 2009, no patients underwent a second surgery for secondary biliary stricture. None of the 3 endoscopic procedures were successful. Those patients benefited from a radiologic procedure with internal-external drainage. A progressive increase in the drain diameter treated the stricture.

Among the two patients with bilioenteric anastomosis, one presented acute severe cholangitis and had radiologic drainage before surgery in 2009. The other patient had a successful radiologic procedure in 2010 with internal-external drainage. 
Two patients without biliary diversion presented secondary biliary stricture during follow-up. Treatment consisted in endoscopic stenting for one patient and radiologic stenting after failure of endoscopic stenting for the other.

\section{Follow-up}

The mean duration of follow-up was $37.2 \pm 25$ months in the whole population, $38.9 \pm 28$ months in the CBP reinsertion group, $43.4 \pm 18$ months in the bilioenteric anastomosis group and $32.1 \pm 27$ months in the no biliary dilation group. Among the 55 patients, five patients died of pathologies independent of the surgical outcomes (pulmonary cancer, acute alcoholic hepatitis, pneumopathy, acute mesenteric ischemia): 3 patients without biliary dilatation and 2 patients with bilioenteric anastomosis. Ten patients were lost to follow-up after 2 years: 8 patients without biliary dilatation and 2 patients with CBD reinsertion.

The presence of biliary dilatation did not influence pain control or exocrine or endocrine insufficiency after 2 years of follow-up (table 3 ).

The presence of bilioenteric anastomosis did not influence long term results after 2 years of follow-up (table 4).

Seven patients (12.7\%) resumed alcohol use. Three patients $(42.8 \%)$ had biliary diversion (1 bilioenteric anastomosis, 2 CBD reinsertion) associated to the Frey procedure. One patient had secondary biliary stricture (previously treated by CBD reinsertion). Among the 4 patients without biliary diversion, one had secondary biliary stricture. 


\section{Discussion}

Duodenum-preserving pancreatic head resection has gradually become the gold standard in the surgical management of painful CP. Conversely, when CP is associated with CBD obstruction, the choice of surgical procedure remains poorly studied and still debated. In the present series, this situation represents half of the cases. The authors demonstrated that associated CBD obstruction to $\mathrm{CP}$ could be efficiently treated by FP. In fact, CBD obstruction did not alter pain relief or the rate of pancreatic insufficiency. However, the present results showed that FP combined with $\mathrm{CBD}$ reinsertion is associated with a greater risk of secondary biliary stricture.

Chronic painful pancreatitis associated with CBD obstruction represents half of the present surgical series. The results confirm the efficiency of FP to treat chronic pancreatic pain. This procedure was associated with pain free control in more than $85 \%$ of cases at 2-year follow-up. The mean rate of severe morbidity $(20 \%)$ was acceptable and mortality was nil. Those rates are in line with the previously published prospective series ${ }^{11-13}$. Therefore, this series confirms that PD is not necessary even when CBD obstruction is associated with a pancreatic head mass. The last indications of $\mathrm{PD}$ in treatment of $\mathrm{CP}$ remain the suspicion of an associated pancreatic cancer or, rarely, a cystic dystrophy in the heterotopic pancreas ${ }^{14-16}$.

In the present series, association of CBD obstruction to a pancreatic head mass did not influence either postoperative outcomes or the long-term results. Pain control was obtained in comparable percentages. In contrast with the previously published results of Cauchy et al., no increase in endocrine insufficiency was found in associated CBD stenosis group ${ }^{17}$.

Regarding late morbidity, rate of secondary biliary stricture after CBD reinsertion in the resection cavity was $60 \%$. This rate was significantly lower in the bilioenteric 
anastomosis group $(p=0.008)$. As expected, the operating time for the FP combined with bilioenteric anastomosis group was longer $(p=0.02)$ but was not associated with greater surgical morbidity. However, incidence of biliary leakage and delayed gastric emptying were higher in the bilioenteric anastomosis group but did not reach significance. This tendency might be explained by the addition of a supplementary anastomosis. The type of biliary diversion recommended in the case of associated CBD obstruction during FP is still unclear in the literature. In 1997, Izbicky noticed that reinsertion of $\mathrm{CBD}$ into the resection cavity was efficient to derive bile but appears to increase the rate of secondary stenosis ${ }^{5,6}$. Cataldegirmen et al. confirmed in 2008 the high rate of secondary biliary stenosis at the site of reinsertion (18\%) in a series of 82 patients ${ }^{18}$. They concluded that this technique offers an alternative to PD but did not compare it to bilioenteric anastomosis associated to FP. This comparison has been performed by Rebibo et al. in a small series of patients ${ }^{6}$. Biliary stricture recurrence appeared in 2 of the 3 patients $(67 \%)$. This rate was greater than in the two other groups (choledochojejunostomy and choledochoduodenostomy), but the significance was discussed due to the small number of patients. The high rate of alkaline reflux gastritis after choledochoduodenostomy encourages performance of choledochojejunal anastomosis ${ }^{19}$. The present series confirmed a greater risk of secondary biliary stricture after CBD reinsertion. As described previously, this result could be explained by an ischemia of the distal CBD during pancreatic head resection caused by opening of the CBD. Another potential explanation for secondary biliary stricture, especially after CBD reinsertion, could be the resumption of alcohol use as previously mentioned by Fischer et al. ${ }^{20}$. 
Secondary biliary stricture was treated successfully in a half of the patients without surgical reoperation. The need for surgical reoperation in the present series was lower than in the series by Cataldegirmen et al. ${ }^{18}$. These authors described a failure of all interventional trans-hepatic procedures and the necessity for reoperation in all patients presenting secondary biliary stricture. This difference is certainly due to an improvement in interventional radiologic or endoscopic procedures over the last decade ${ }^{21}$. Therefore, the 3 first patients with secondary biliary stricture in the present cohort systematically underwent a second surgery. Those patients were operated between 2007 and 2009. The decision of a re-operation was probably taken at this time because of the lack of knowledge on the results of radiologic or endoscopic procedures. Since 2009, interventional endoscopic or radiologic procedures have become the first line of treatment for secondary biliary stricture.

Of course, some possible weaknesses of the present study should be mentioned. First, the limited number of patients in this series is one of its critical points. This could be partly explained by the limited indications of FP combined with biliary diversion. An isolated $\mathrm{CBD}$ obstruction caused by $\mathrm{CP}$ is typically treated endoscopically. Second, near $20 \%$ of patients were lost to follow up. However, in the biliary dilatation group, they were all in the CBP reinsertion group, which did not alter our conclusion. Third, the choice of biliary diversion at the discretion of the surgeon is another bias. A randomized study is needed to confirm the results of this series.

The Frey procedure has become a standard surgical treatment for chronic painful pancreatitis. Biliary diversion could be combined when CBD stricture was present without increasing morbidity or affecting pain control. Although associated with a longer operating time, bilioenteric anastomosis combined with the Frey procedure 
achieves efficient biliary diversion with a lower rate of secondary biliary stricture compared with CBD reinsertion in the resection cavity. 


\section{References}

1. Braganza JM, Lee SH, McCloy RF, McMahon MJ. Chronic pancreatitis. The Lancet. 2011;377(9772):1184-97.

2. Abdallah AA, Krige JEJ, Bornman PC. Biliary tract obstruction in chronic pancreatitis. HPB. 2007;9(6):421-8.

3. Andersen DK, Frey CF. The evolution of the surgical treatment of chronic pancreatitis. Ann Surg. 2010;251(1):18-32.

4. Frey CF, Smith GJ. Description and rationale of a new operation for chronic pancreatitis. Pancreas. 1987;2(6):701-7.

5. Izbicki JR, Bloechle C, Broering DC, Broelsch CE. Reinsertion of the distal common bile duct into the resection cavity during duodenum-preserving resection of the head of the pancreas for chronic pancreatitis. $\mathrm{Br} \mathrm{J}$ Surg. 1997;84(6):791-2.

6. Rebibo L, Yzet T, Cosse C, Delcenserie R, Bartoli E, Regimbeau J-M. Frey procedure for the treatment of chronic pancreatitis associated with common bile duct stricture. Hepatobiliary Pancreat Dis Int. 2013;12(6):637-44.

7. Dindo D, Demartines N, Clavien P-A. Classification of surgical complications: a new proposal with evaluation in a cohort of 6336 patients and results of a survey. Ann Surg. 2004;240(2):205-13. 
8. Bassi C, Dervenis C, Butturini G, Fingerhut A, Yeo C, Izbicki J, et al. Postoperative pancreatic fistula: an international study group (ISGPF) definition. Surgery. 2005;138(1):8-13.

9. Wente MN, Bassi C, Dervenis C, Fingerhut A, Gouma DJ, Izbicki JR, et al. Delayed gastric emptying (DGE) after pancreatic surgery: a suggested definition by the International Study Group of Pancreatic Surgery (ISGPS). Surgery. 2007;142(5):761-8.

10. Wente MN, Veit JA, Bassi C, Dervenis C, Fingerhut A, Gouma DJ, et al. Postpancreatectomy hemorrhage (PPH): an International Study Group of Pancreatic Surgery (ISGPS) definition. Surgery. 2007;142(1):20-5.

11. Falconi M, Bassi C, Casetti L, Mantovani W, Mascetta G, Sartori N, et al. Longterm results of Frey's procedure for chronic pancreatitis: a longitudinal prospective study on 40 patients. J Gastrointest Surg. 2006;10(4):504-10.

12. Strate T, Taherpour Z, Bloechle C, Mann O, Bruhn JP, Schneider C, et al. Longterm Follow-up of a Randomized Trial Comparing the Beger and Frey Procedures for Patients Suffering From Chronic Pancreatitis. Ann Surg. 2005;241(4):591-8.

13. Roch AMD, Brachet D, Lermite E, Pessaux P, Arnaud J-P. Frey Procedure in Patients with Chronic Pancreatitis: Short and Long-term Outcome from a Prospective Study. J Gastrointest Surg. 2012;16(7):1362-9. 
14. Merdrignac A, Sulpice L, Rayar M, Rohou T, Quehen E, Zamreek A, et al. Pancreatic head cancer in patients with chronic pancreatitis. Hepatobiliary Pancreat Dis Int. 2014;13(2):192-7.

15. Thomas $\mathrm{H}$, Marriott $\mathrm{P}$, Portmann B, Heaton N, Rela M. Cystic dystrophy in heterotopic pancreas: a rare indication for pancreaticoduodenectomy. Hepatobiliary Pancreat Dis Int. 2009;8(2):215-7.

16. Tison C, Regenet N, Meurette G, Mirallié E, Cassagnau E, Frampas E, et al. Cystic dystrophy of the duodenal wall developing in heterotopic pancreas: report of 9 cases. Pancreas. 2007;34(1):152-6.

17. Cauchy F, Regimbeau JM, Fuks D, Balladur P, Tiret E, Paye F. Influence of bile duct obstruction on the results of Frey's procedure for chronic pancreatitis. Pancreatology. 2014;14(1):21-6.

18. Cataldegirmen G, Bogoevski D, Mann O, Kaifi JT, Izbicki JR, Yekebas EF. Late morbidity after duodenum-preserving pancreatic head resection with bile duct reinsertion into the resection cavity. Br J Surg. 2008;95(4):447-52.

19. Mihmanli M, Isgör A, Erzurumlu K, Kabukcuoglu F, Mihmalli I. Long-term results of choledochoduodenostomy and T-tube drainage. Hepatogastroenterology. $1996 ; 43(12): 1480-3$.

20. Fischer TD, Gutman DS, Warner EA, Trevino JG, Hughes SJ, Behrns KE. Local pancreatic head resection: the search for optimal indications through quality of life assessments. Am J Surg. 2015;210(3):417-23. 
21. Janssen JJ, Delden OM van, Lienden KP van, Rauws EAJ, Busch ORC, Gulik TM van, et al. Percutaneous Balloon Dilatation and Long-Term Drainage as Treatment of Anastomotic and Nonanastomotic Benign Biliary Strictures. Cardiovasc Intervent Radiol. 2014;37(6):1559-67. 


\section{Legends to tables}

Table 1: Preoperative, perioperative and postoperative characteristics of patients according to biliary dilatation status $(n=55)$.

Table 2: Preoperative, perioperative and postoperative outcome characteristics of patients with preoperative biliary dilatation according to biliary diversion technique $(n=29)$.

Table 3: 2 year follow-up according to biliary dilatation status $(n=41)$.

Table 4: 2 year follow-up according to presence of bilioenteric anastomosis $(n=41)$. 


\section{Tables}

Table 1: Preoperative, perioperative and postoperative characteristics of patients according to biliary dilatation status $(\mathrm{n}=55)$.

\begin{tabular}{|c|c|c|c|}
\hline & Biliary dilatation & No biliary dilatation & \multirow[b]{2}{*}{ p-value } \\
\hline & $n=29(53)$ & $\mathrm{n}=26(47)$ & \\
\hline Preoperative data & & & \\
\hline Age (mean $\pm S D)$ & $48.9 \pm 9.1$ & $48.1 \pm 11.2$ & 0.83 \\
\hline Range & $30-66$ & $18-68$ & \\
\hline Gender (ratio female:male) & $2: 27$ & $2: 24$ & \\
\hline $\mathrm{BMI}(\operatorname{mean} \pm \mathrm{SD})$ & $21.6 \pm 3.1$ & $21.1 \pm 2.1$ & 0.29 \\
\hline Range & $15.7-27.2$ & $17.3-25.2$ & \\
\hline Diabetes & 10 & $6(23)$ & 0.4 \\
\hline Exocrine insufficiency & 24 (83) & $20(77)$ & 0.84 \\
\hline ASA score & & & 0.42 \\
\hline I & $0(0)$ & $2(8)$ & \\
\hline II & $24(83)$ & 20 (77) & \\
\hline III & $5(17)$ & 4 (15) & \\
\hline Previous pancreatic surgery & $6(21)$ & $4(15)$ & 0.73 \\
\hline Perioperative data & & & \\
\hline Operation time (min, mean \pm SD) & $288.6 \pm 57.4$ & $260.2 \pm 52.7$ & 0.08 \\
\hline Range & $180-420$ & $165-380$ & \\
\hline Transfusion & $0(0)$ & $3(12)$ & 0.09 \\
\hline Postoperative outcomes & & & \\
\hline Pancreatic Fistula & $3(10)$ & $2(8)$ & 1 \\
\hline Biliary Fistula & $2(7)$ & $0(0)$ & 0.49 \\
\hline Delayed gastric emptying & $3(10)$ & $6(23)$ & 0.28 \\
\hline Wound infection & $3(10)$ & $4(15)$ & 0.69 \\
\hline Haemorrhage & $3(10)$ & $8(31)$ & 0.09 \\
\hline Clavien-Dindo classification & & & 0.90 \\
\hline l & $16(55)$ & $12(46)$ & \\
\hline II & $8(28)$ & $8(31)$ & \\
\hline Illa & $1(3)$ & $0(0)$ & \\
\hline Illlb & $2(7)$ & $2(8)$ & \\
\hline IVa & $2(7)$ & $3(12)$ & \\
\hline $\mathrm{IVb}$ & $0(0)$ & $1(4)$ & \\
\hline V & $0(0)$ & $0(0)$ & \\
\hline Hospitalization duration (days, mean $\pm S D$ ) & $11.3 \pm 4.9$ & $14.8 \pm 19.7$ & 0.84 \\
\hline Range & $7-26$ & 6-108 & \\
\hline Re-admission & $4(14)$ & $6(23)$ & 0.49 \\
\hline
\end{tabular}

The number of patients presenting pancreatic fistula, delayed gastric emptying or haemorrhage are equal to the sum of all grades to permit statistical analyses. Values in parentheses are percentages. 
Table 2: Preoperative, perioperative and postoperative outcome characteristics of patients with preoperative biliary dilatation according to biliary diversion technique $(n=29)$.

\begin{tabular}{|c|c|c|c|}
\hline & $\begin{array}{c}\begin{array}{c}\text { Bilioenteric } \\
\text { anastomosis }\end{array} \\
n=19(66) \\
\end{array}$ & $\begin{array}{c}\text { Common bile duct } \\
\text { reinsertion } \\
n=10(34) \\
\end{array}$ & p-value \\
\hline Preoperative data & & & \\
\hline Age $($ mean $\pm s d)$ & $48.2 \pm 9.4$ & $50.4 \pm 8.8$ & 0.43 \\
\hline Range & $30-66$ & $35-61$ & \\
\hline Gender ratio (female:male) & $2: 17$ & $0: 10$ & 0.53 \\
\hline BMI (mean $\pm s d)$ & $21.6 \pm 3.2$ & $21.6 \pm 3$ & 0,94 \\
\hline Range & $1574-2718$ & $\begin{array}{r}15.97- \\
25.73\end{array}$ & \\
\hline Diabetes & $6(32)$ & $4(40)$ & 0.69 \\
\hline Exocrine insufficiency & $14(74)$ & $10(100)$ & 0.13 \\
\hline ASA score & & & 0.3 \\
\hline II & $17(89)$ & $7(70)$ & \\
\hline III & $2(11)$ & $3(30)$ & \\
\hline Previous abdominal surgery & $5(26)$ & $1(10)$ & 0.63 \\
\hline Perioperative data & & & \\
\hline Operation time (min, mean \pm SD) & $303.1 \pm 52.7$ & $261 \pm 58.2$ & 0.02 \\
\hline Range & $240-420$ & $180-380$ & \\
\hline Transfusion & $0(0)$ & $0(0)$ & \\
\hline Postoperative outcomes & & & \\
\hline Pancreatic Fistula & $1(5)$ & $2(20)$ & 0.26 \\
\hline Biliary Fistula & $2(11)$ & $0(0)$ & 0.53 \\
\hline Delayed gastric emptying & $3(16)$ & $0(0)$ & 0.53 \\
\hline Wound infection & $2(11)$ & 1 (10) & 1 \\
\hline Haemorrhage & $2(11)$ & $1(10)$ & 1 \\
\hline Clavien-Dindo classification & & & 0.19 \\
\hline I & $9(47)$ & 7 (70) & \\
\hline II & 7 (37) & 1 (10) & \\
\hline IIla & $0(0)$ & 1 (10) & \\
\hline Illb & $2(11)$ & $0(0)$ & \\
\hline IVa & $1(5)$ & 1 (10) & \\
\hline $\mathrm{IVb}$ & $0(0)$ & $0(0)$ & \\
\hline V & $0(0)$ & $0(0)$ & \\
\hline Hospitalization duration (days, mean $\pm S D$ ) & $11.3 \pm 4.9$ & $11.3 \pm 5.1$ & 0.87 \\
\hline Re admission & $3(16)$ & $1(10)$ & 0.63 \\
\hline $\begin{array}{l}\text { Secondary biliary stricture } \\
\text { Type of re intervention }\end{array}$ & $2(11)$ & $6(60)$ & 0.008 \\
\hline Radiologic & 2 & 3 & \\
\hline Endoscopic & 0 & 3 & \\
\hline Surgery & 1 & 3 & \\
\hline
\end{tabular}

The number of patients presenting pancreatic fistula, delayed gastric emptying or haemorrhage are equal to the sum of all grades to permit statistical analyses. Values in parentheses are percentages. 
Table 3: 2 year follow-up according to biliary dilatation status $(n=41)$.

\begin{tabular}{|lrrr|}
\hline & $\begin{array}{c}\text { Biliary dilatation } \\
\mathbf{n = 2 6 ( 6 3 )}\end{array}$ & $\begin{array}{c}\text { No biliary dilatation } \\
\mathbf{n}=\mathbf{1 5}(\mathbf{3 7})\end{array}$ & $\mathbf{p}$-value \\
\cline { 2 - 4 } Pain control & $25(96)$ & $13(87)$ & 0.54 \\
Yes & $1(4)$ & $2(13)$ & \\
No & & & \\
Diabetes & $16(61)$ & $8(53)$ & 0.74 \\
Yes & $10(38)$ & $7(47)$ & \\
No & $2(8)$ & $2(13)$ & 0.61 \\
Pancreatic enzyme replacement & $24(92)$ & $13(87)$ & \\
Yes & & & \\
No & 24 & & \\
\hline
\end{tabular}

Values in parentheses are percentages.

Table 4: 2 year follow-up according to presence of bilioenteric anastomosis $(n=41)$.

\begin{tabular}{|c|c|c|c|}
\hline & $\begin{array}{c}\text { Bilioenteric } \\
\text { anastomosis } \\
n=18(44)\end{array}$ & $\begin{array}{c}\text { Other } \\
\mathrm{n}=23(56)\end{array}$ & p-value \\
\hline Pain control & & & 0.24 \\
\hline Yes & $18(100)$ & $20 \quad(87)$ & \\
\hline No & $0(0)$ & $3(13)$ & \\
\hline Diabetes & & & 0.52 \\
\hline Yes & $12(67)$ & 12 (52) & \\
\hline No & $6(33)$ & $11(48)$ & \\
\hline \multicolumn{4}{|c|}{ Pancreatic enzyme replacement } \\
\hline Yes & $10 \quad(56)$ & $15(65)$ & 0.74 \\
\hline No & $8(44)$ & $8(35)$ & \\
\hline
\end{tabular}

Values in parentheses are percentages. 